Jurnal Optimalisasi

Vol 3 Nomor 5 OKTOBER 2017

P. ISSN : 2477-5479

E. ISSN : 2502-0501

\title{
PENERAPAN METODE ANTRIAN DALAM MENENTUKAN FASILITAS YANG OPTIMAL PADA SPBU MAWADDAH
}

\author{
Diana Khairani Sofyan ${ }^{* 1}$, Sri Meutia ${ }^{2}$ \\ ${ }^{1,2}$ Jurusan Teknik Industri, Fakultas Teknik, Universitas Malikussaleh, Lhokseumawe \\ e-mail: ${ }^{* 1}$ hatikue@yahoo.com
}

\begin{abstract}
Gas stations Mawaddah Is one of the gas stations located in the Village Batuphat East Lhokseumawe. The gas station has 5 oil pumps consisting of premium with two pumps, diesel consists of two pumps, and pertamax consists of one pump. Preliminary data have been made regarding the arrival rate of vehicles in each pump, which is a two-wheeled premium filling pump of 195 vehicles, four or more 166 wheels or four wheels filling pumps, four or more diesel fuel pumps of 156 and a feeding pump of 138 vehicles. High vehicle arrival rate resulted in queue. To calculate the level of service has never been done so it is not known the maximum time for service on each pump. The research method used is queuing model related to arrival rate and service level, with result of research which obtained is vehicle arrival rate at each pump that is 2 wheel of premium gasoline pump is 2.59 minutes. The premium 4 wheels charging pump is 6.98. The 4 wheelers diesel fuel pump is 5.97 minutes and the first charging pump is 6.65 minutes with the facility number 1. Vehicle service rates of premium 2 and 4 wheelers are 15.52 minutes and 14.11 minutes, 4 wheel diesel fuel pump is 14.21 minutes and the first feed pump is 13.55 minutes with scenario design on each pump is Scenario 1 with 2 pumps, Probability of medium system empty 0.87500, Number of subscribers in the system and number of customers waiting in the queue of each 1 customer, the average customer time in the system 0.06696 minutes and waiting time as long as the customer in the queue 0.00030 minutes.
\end{abstract}

Keywords: Queue, facility, arrival rate, service rate.

\section{PENDAHULUAN}

\subsection{Latar Belakang}

Antrian adalah kejadian yang sering terjadi dalam kehidupan sehari-hari. Antrian seperti menunggu di depan loket untuk mendapatkan tiket kereta api atau tiket bioskop, pada pintu jalan tol, pada bank, pada kasir supermarket, pada SPBU dan situasi-situasi yang lain merupakan kejadian yang sering ditemui dalam lingkungan masyarakat. Studi tentang antrian bukan merupakan hal yang baru. Antrian timbul disebabkan oleh kebutuhan akan layanan.

SPBU Mawaddah yang berada di Desa Batuphat Timur Lhokseumawe Jl. Medan Banda-Aceh. SPBU tersebut memiliki sejumlah fasilitas lain di dalamnya yang terdiri dari musholla, minimarket, ATM. SPBU ini memiliki 5 pompa minyak yang terdiri dari premium terdiri atas dua pompa, solar terdiri atas dua pompa, dan pertamax yang terdiri atas satu pompa. SPBU ini akan berusaha memuaskan pelanggan, mengutamakan pada kepentingan pelanggan, dan berkomitmen untuk memberikan pelayanan terbaik kepada 
pelanggan. Serta pada fasilitas yang terdapat di dalam SPBU lainnya selalu memperhatikan kebersihan dan keamanan lingkungan sekitarnya.

Data pengamatan awal yang telah dilakukan adalah mengenai tingkat kedatangan kendaraan pada setiap pompa, yaitu pompa pengisian premium roda dua sebanyak 195 kendaraan, pompa pengisian premium roda empat atau lebih sebanyak 166 kendaraan, pompa pengisian solar roda empat atau lebih sebanyak 156 dan pompa pengisian pertamax sebanyak 138 kendaraan. Tingkat kedatangan kendaraan yang tinggi mengakibatkan terjadinya antrian. Untuk perhitungan tingkat pelayanan belum pernah dilakukan sehingga tidak diketahui waktu maksimal bagi pelayanan pada masing-masing pompa. Data awal yang telah dilakukan merupakan data 1 (satu) hari kerja yaitu dari jam 07.00-17.00 Wib dengan pencatatan berdasarkan sampling acak sederhana.

Berdasarkan hal tersebut, pengisian bagi setiap pompa sangat tidak efektif, melihat banyaknya antrian, ini sangat berpengaruh pada tingkat kepuasan konsumen. Keadaan ini sangat bertentangan dengan Visi SPBU Mawaddah yang senantiasa berusaha memberikan pelayanan yang terbaik, sehingga pelanggan puas dalam mengisi bahan bakar umum (BBM) baik yang memiliki kendaraan roda dua maupun roda empat dan sebagainya. Berdasarkan uraian tersebut maka dilakukan penelitian mengenai "Penerapan Metode Antrian Dalam Menentukan Fasilitas Yang Optimal Pada SPBU Mawaddah Batuphat Timur-Aceh Utara".

\subsection{Masalah penelitian}

Permasalahan yang diteliti adalah permasalahan yang berkaitan dengan fasilitas pada SPBU Mawaddah, dalam hal ini rancangan skenario kedatangan dan pelayanan kendaraan roda dua dan roda empat di analisis sehingga diperoleh penentuan fasilitas yang optimal pada SPBU.

\subsection{Tujuan yang ingin dicapai}

Adapun tujuan yang ingin dicapai adalah sebagai berikut:

1. Menentukan laju kedatangan dan laju pelayanan kendaraan pada pompa.

2. Menentukan rancangan skenario pada pompa.

3. Menganalisis tingkat pelayanan yang optimal dan panjang garis tunggu pada antrian.

4. Menentukan fasilitas pengisian kendaraan roda dua maupun roda empat.

\section{TINJAUAN PUSTAKA}

\subsection{Antrian}

Teori antrian adalah teori yang menyangkut study matematis dari antrian-antrian atau baris-baris penungguan. Formasi baris-baris penungguan merupakan sesuatu yang biasa terjadi apabila kebutuhan akan suatu pelayanan melebihi kapasitas yang tersedia untuk menyelenggarakan kapasitas tersebut. Apabila pelayanan terlalu banyak maka akan memerlukan ongkos yang besar. Sebaliknya jika kapasitas pelayanan kurang maka akan terjadi baris penungguan dalam waktu yang cukup lama dan juga akan menimbulkan ongkos baik berupa ongkos sosial, kehilangan langganan ataupun pengangguran kerja. Yang menjadi tujuan utama teori antrian adalah mencapai keseimbangan antara ongkos pelayanan dengan ongkos yang disebabkan oleh adanya waktu menunggu tersebut [1].

\subsection{Tingkat Pelayanan Optimal}

Optimalisasi berasal dari kata dasar optimal yang berarti yang terbaik. Jadi optimalisasi adalah proses pencapaian suatu pekerjaan dengan hasil dan keuntungan yang 
besar tanpa harus mengurangi mutu dan kualitas dari sutau pekerjaan. Optimalisasi didapatkan dengan menyeimbangkan antrian akan dapat diperoleh banyak ukuran kinerja sebuah sistem antrian terhadap tingkat kepuasan pelanggan, dengan melihat beberapa hal penting sebagai berikut [2]:

1. Waktu rata-rata yang dihabiskan oleh pelanggan didalam antrian.

2. Panjang antrian rata-rata.

3. Waktu rata-rata yang dihabiskan oleh pelanggan dalam sistem

4. Jumlah pelanggan rata-rata didalam sistem.

5. Probabilitas fasilitas pelayanan akan kosong.

6. Faktor utilisasi sistem.

7. Probabilitas sejumlah pelanggan berada dalam sistem.

\subsection{Biaya Fasilitas}

Biaya fasilitas adalah biaya yang muncul karena organisasi harus mengadakan tambahan investasi guna menanbah fasilitas pelayanan agar tingkat pelayanan $\mu$ meningkat. Biaya ini pada dasarnya terdiri dari biaya tetap untuk tambahan fasilitas dan biaya operasional. Kareana tolak ukur kinerja penambahan fasilitas itu adalah penurunan tingkat pelayanan $\mu$, maka satuan biaya tetap penambahan fasilitas dan satuan biaya operasional variabel harus diukur berdasarkan satuan tersebut [3].

Dengan demikian biaya fasilitas adalah :

Dimana :

$$
\begin{aligned}
& \text { Biaya fasilitas }=B_{F} \cdot \mu \\
& B_{T A}=B_{F} \cdot \mu+B_{A} \frac{\lambda}{\mu-\lambda}
\end{aligned}
$$

$B_{T A}$ : Biaya total antrian

$B_{F}$ : Biaya fasilitas

$B_{A}$ : Biaya antri

$\mu$ : Tingkat pelayanan

$\lambda$ : Tingkat kedatangan

Untuk $\mu$ yang akan menandai tingkat pelayanan atau $\mu$ optimal yang akan menghasilkan biaya total antrian minimum yaitu sebagai berikut.

$$
\mu \text { optimum }=\lambda+\sqrt{\frac{B_{A} \cdot \lambda}{B_{z}}}
$$

\subsection{Tingkat Pelayanan}

Waktu rata-rata untuk melayani satu pelanggan disebut tingkat pelayanan (service rate) dengan notasi $\mu$. Jika kapasitas fasilitas pelayanan mampu melayani 4 pelanggan per jam artinya rata-rata tingkat pelayanan (service rate) adalah $\mu=4 /$ jam maka rata-rata waktu pelayanan (service time) setiap pelanggan $1 / 4$ jam (15 menit) atau $1 / \mu$. Meskipun tingkat pelayanan mungkin konstan, misal dalam kapasitas pelayanan yang otomatis, namun sangat sering tingkat pelayanan itu terdistribusi secara acak (random) [4]. Disiplin pelayanan berkaitan erat dengan urutan pelayanan bagi pelanggan yang memasuki fasilitas pelayanan. Disiplin pelayanan ini terbagi menjadi empat bentuk yaitu sebagai berikut [4]:

1. FCFS (First Come, First Served/datang pertama, dilayani pertama) merupakan suatu peraturan dimana pelanggan yang dilayani terlebih dahulu adalah pelanggan yang 
datang pertama kali. Contohnya dapat dilihat pada antrian diloket-loket penjualan kercis.

2. LCFS (Last Come, First Served/datang terakhir, dilayani pertama) merupakan antrian dimana pelanggan yang datang terakhirlah yang akan dilayani terlebih dahulu. Contohnya pada sistem bongkar muat barang dalam truk, dimana barang yang masuk terakhir akan keluar terlebih dahulu.

3. SIRO (Service In Random Number/pelayanan dalam urutan acak) merupakan salah satu disiplin antrian dimana pelayanan dilakukan dengan urutan acak (Random Order). Contohnya dapat ditemukan didalam suatu kegiatan arisan, dimana dilakukan berdasarkan undian.

4. Antrian prioritas (Priority Queue) merupakan prioritas pelayanan yang dilakukan khusus kepada pelanggan utama (VIP Customer).

\subsection{Struktur dan Antrian Dasar}

Sebuah fasilitas pelayanan dalam sebuah sistem mungkin hanya terdiri satu kali proses, artinya setelah selesai proses pelayanan segera keluar dari sistem.

Ada empat struktur antrian dasar adalah sebagai berikut [5]:

1. Single Channel Single Phase

Pada struktur antrian ini, sabjek memanggil populasi yang dilayani akan datang, masuk dan membentuk antrian pada satu barisan/aliran pelayanan dan selanjutnya akan berhadapan dengan satu fasilitas pelayanan.

2. Single Channel Multiple Phase

Pada struktur antrian ini, sabjek pemanggilan populasi yang dilayani akan datang, masuk dan membentuk antrian pada beberapa aliran pelayanan dan selanjutnya akan berhadapan dengan satu fasilitas pelayanan sampai pelayanan selesai. Multiple Channel Single Phase.

Pada struktur antrian ini, sabjek pemanggilan populasi yang dilayani akan datang, masuk dan membentuk antrian pada satu baris/aliran pelayanan dan selanjutnya akan berhadapan dengan beberapa fasilitas identik yang pararel.

3. Multiple Channel Multi Phase

Pada struktur antrian ini, sabjek pemanggilan populasi yang akan datang dan masuk kedalam sistem pelayanan yang dioperasikan oleh beberapa fasilitas pelayanan pararel yang identik menuju ke fasilitas pelayanan setelahnya sampai pelayanan selesai.

\subsection{Pola Kedatangan}

Fungsi peluang Poisson digunakan untuk menggambarkan tingkat kedatangan dengan asumsi bahwa jumlah kedatangan adalah acak. Dimana persamaannya fungsi

Peluang Poisson adalah sebagai berikut : $P(x)=\frac{\lambda^{x} \cdot e^{-\lambda}}{x !}$

Dimana :

$\mathrm{P}(\mathrm{x})=$ Peluang bahwa ada $\mathrm{x}$ pelanggan dalam sistem

$\lambda \quad=$ Harga rata-rata kecepatan kedatangan

$\mathrm{e} \quad=$ Bilangan navier $(\mathrm{e}=2,71828)$

$\mathrm{x} \quad=$ Bilangan cacah $(0,1,2,3, \ldots)$

Lama Pelayanan yang dihitung sejak kedatangan pelanggan dalam sistem antrian sampai selesai pelayanan mengikuti Distribusi Eksponensial yang persamaannya sebagai berikut $[3,4]$ :

$\mathrm{P}(\mathrm{t})=\mu e^{-\mu e}$ 
Dimana:

$\mu=$ Rata-rata lama pelayanan

$\mathrm{e}=$ Bilangan navier $(\mathrm{e}=2,71828)$

$\mathrm{t}=$ waktu lamanya pelayanan tiap unit.

Model multi kanal fase tunggal bisa dilihat pada stasiun pengisian BBM yang mamiliki beberapa mesin pompa dimana setiap pelanggan yang datang bebas milih pompa mana yang akan mengisi bahan bakarnya dan setelah itu langsung keluar. Ketika ada lebih dari satu fasilitas pelayanan, maka pelanggan akan segera masuk ke fasilitas yang kosong atau fasilitas yang baru saja ditinggalkan oleh pelanggan. Model-model antrian multi kanal fase tunggal adalah sebagai berikut [5]:

1. Probabilitas tidak ada pelanggan dalam sistem

$$
P_{0}=\frac{1}{\sum_{n=0}^{k-1}\left[\frac{1}{n !}\left(\frac{\lambda}{\mu}\right)^{n}\right]+\frac{\left(\frac{\lambda}{\mu}\right)^{k}}{k !\left(1-\frac{\lambda}{k \cdot \mu}\right)}}
$$

2. Rata-rata jumlah pelanggan dalam garis tuggu atau panjang antrian $\left(P_{A}\right)$

$$
P_{A}=\frac{\left(\frac{\lambda}{\mu}\right)^{k} \lambda \cdot \mu}{(k-1) !(k \cdot \mu-\lambda)^{2}} \cdot P_{0}
$$

3. Waktu rata-rata pelanggan di garis tunggu atau waktu antri

$$
\left(W_{A}\right), W_{A}=\frac{P_{A}}{\lambda}
$$

4. Waktu rata-rata pelanggan dalam sistem $\left(W_{S}\right)$

$$
W_{S}=W_{A}+\frac{1}{\mu}
$$

5. Jumlah rata-rata pelanggan dalam sistem atau panjang sistem $\left(P_{S}\right)$

$$
P_{S}=P_{A}+\frac{\lambda}{\mu}
$$

\section{METODE PENELITIAN}

Metode penelitian yang digunakan pada penelitian ini adalah metode antrian, dimana dilakukan perhitungan penentuan fasilitas yang optimal dengan rancangan awal penelitian yaitu mengumpukan data melalui pengamatan langsung dan wawancara dengan karyawan serta manajer SPBU. Kemudian menghitung data yang dikumpulkan berdasarkan model antrian sesuai denga perhitungan yang dibutuhkan, setelah hasil perhitungan diperoleh maka dilanjutkan dengan analisis data. Data yang akan diteliti sekitar pukul 07.00-16.55 Wib dengan pengambilan waktu secara random (acak) dengan interval waktu lima menit dan selama 60 kali pengamatan. Data yang dikumpulkan merupakan data primer yaitu pengamatan terhadap kedatangan kendaraan $(\lambda)$ dan 
pengamatan terhadap waktu pelayanan $(\mu)$ dan data sekunder yaitu teori yang terkait dan informasi yang diperoleh berdasarkan data catatan dari perusahaan.

\section{HASIL DAN PEMBAHASAN}

\subsection{Laju Kedatangan Kendaraan}

Jumlah kedatangan kendaraan dicatat selama 6 hari dengan interval waktu lima menit, dari hasil 60 kali pengamatan diperoleh frekuensi kedatangan untuk masing-masing pompa pengisian bahan bakar umum seperti Tabel 1 berikut:

Tabel 1 Laju Kedatangan Kendaraan Pada Masing-Masing Pompa

\begin{tabular}{llcc}
\hline No & \multicolumn{1}{c}{ Pompa Pengisian } & $\begin{array}{c}\text { Laju Kedatangan }(\lambda) \\
\text { Per Menit }\end{array}$ & Jumlah Fasilitas \\
\hline 1 & Pompa pengisian premium roda 2 & 2.59 & 2 \\
2 & Pompa pengisian premium roda 4 & 6.98 & 2 \\
3 & Pompa pengisian solar roda 4 & 5.97 & 1 \\
4 & Pompa pengisian pertamax & 6.65 & 1 \\
\hline
\end{tabular}

\subsection{Laju Pelayanan Kendaraan}

Jumlah pelayanan kendaraan dicatat selama 6 hari dengan interval waktu lima menit, dari hasil 60 kali pengamatan diper2berikut:

Tabel 2 Laju Pelayanan Kendaraan Pada Masing-Masing Pompa

\begin{tabular}{clcc}
\hline No & \multicolumn{1}{c}{ Pompa Pengisian } & $\begin{array}{c}\text { Laju Kedatangan }(\mu) \text { Per } \\
\text { Menit }\end{array}$ & $\begin{array}{c}\text { Jumlah } \\
\text { Fasilitas }\end{array}$ \\
\hline 1 & Pompa pengisian premium roda 2 & 15.52 & 2 \\
2 & Pompa pengisian premium roda 4 & 14.11 & 2 \\
3 & Pompa pengisian solar roda 4 & 14.21 & 1 \\
4 & Pompa pengisian pertamax & 13.55 & 1 \\
\hline
\end{tabular}

\subsection{Rancangan Skenario}

Rancangan skenario pada setiap pompa dapat dilihat pada Tabel 3-Tabel 6 berikut.

Tabel 3. Rancangan Skenario Pada Pompa Premium Kendaraan Roda Dua

\begin{tabular}{cccccccccc}
\hline Skenario & C & Lambda & Mu & L'da eff & P0 & Ls & Lq & Ws & Wq \\
\hline 1 & 2 & 2,00000 & 15,00000 & 2,00000 & 0,87500 & 0,13393 & 0,00060 & 0,06696 & 0,00030 \\
2 & 1 & 2,00000 & 15,00000 & 2,00000 & 0,87500 & 0,13393 & 0,00060 & 0,06696 & 0,00030 \\
3 & 1 & 2,00000 & 15,00000 & 2,00000 & 0,86667 & 0,15385 & 0,02051 & 0,07692 & 0,01026 \\
4 & 1 & 2,00000 & 15,00000 & 2,00000 & 0,86667 & 0,15385 & 0,02051 & 0,07692 & 0,01026 \\
\hline
\end{tabular}

Tabel 4. Rancangan Skenario Pada Pompa Premium Kendaraan Roda Empat

\begin{tabular}{cccccccccc}
\hline Skenario & C & Lambda & Mu & L'da eff & P0 & Ls & Lq & Ws & Wq \\
\hline 1 & 2 & 6,00000 & 14,00000 & 6,00000 & 0,64706 & 0,44920 & 0,02063 & 0,07487 & 0,00344 \\
2 & 1 & 6,00000 & 14,00000 & 6,00000 & 0,64706 & 0,44920 & 0,02063 & 0,07487 & 0,00344 \\
3 & 1 & 6,00000 & 14,00000 & 6,00000 & 0,57143 & 0,75000 & 0,32143 & 0,12500 & 0,05357 \\
4 & 1 & 6,00000 & 14,00000 & 6,00000 & 0,57143 & 0,75000 & 0,32143 & 0,12500 & 0,05357 \\
\hline
\end{tabular}

Tabel 5. Rancangan Skenario Pada Pompa Solar Kendaraan Roda Empat

\begin{tabular}{cccccccccc}
\hline Skenario & C & Lambda & Mu & L'da eff & P0 & Ls & Lq & Ws & Wq \\
\hline 1 & 2 & 5,00000 & 14,00000 & 5,00000 & 0,69697 & 0,36891 & 0,01176 & 0,07378 & 0,00235
\end{tabular}




\begin{tabular}{llllllllll}
2 & 1 & 5,00000 & 14,00000 & 5,00000 & 0,69697 & 0,36891 & 0,01176 & 0,07378 & 0,00235 \\
3 & 1 & 5,00000 & 14,00000 & 5,00000 & 0,64286 & 0,55556 & 0,19841 & 0,11111 & 0,03968 \\
4 & 1 & 5,00000 & 14,00000 & 5,00000 & 0,64286 & 0,55556 & 0,19841 & 0,11111 & 0,03968 \\
\hline
\end{tabular}

Tabel 6. Rancangan Scenario Pada Pompa Pertamax

\begin{tabular}{cccccccccc}
\hline Skenario & C & Lambda & Mu & L'da eff & P0 & Ls & Lq & Ws & Wq \\
\hline 1 & 2 & 6,00000 & 13,00000 & 6,00000 & 0,62500 & 0,48750 & 0,02596 & 0,08125 & 0,00433 \\
2 & 1 & 6,00000 & 13,00000 & 6,00000 & 0,62500 & 0,48750 & 0,02596 & 0,08125 & 0,00433 \\
3 & 1 & 6,00000 & 13,00000 & 6,00000 & 0,53846 & 0,85714 & 0,39560 & 0,14286 & 0,06593 \\
4 & 1 & 6,00000 & 13,00000 & 6,00000 & 0,53846 & 0,85714 & 0,39560 & 0,14286 & 0,06593 \\
\hline
\end{tabular}

\subsection{Analisis Tingkat Pelayanan Optimal}

Diketahui :

$\lambda=22,19$ menit $\mu=57,39$ menit

Tingkat pelayanan optimal pada pompa premium roda dua

$$
\begin{aligned}
\text { Optimal } & =\lambda+\sqrt{\frac{B_{A} \cdot \lambda}{B_{F}}} \\
& =2+\sqrt{\frac{57,39 \cdot 2}{22,19}} \\
& =2+5,17 \\
& =7,17 \text { menit }
\end{aligned}
$$

Tingkat pelayanan optimal pada pompa premium kendaraan roda empat

$$
\text { Optimal }=\lambda+\sqrt{\frac{B_{A} \cdot \lambda}{B_{F}}}=6+\sqrt{\frac{57,39.6}{22,19}}=6+15,51=21,51 \text { menit }
$$

Tingkat pelayanan optimal pada pompa solar kendaraan roda empat

$$
\text { Optimal }=\lambda+\sqrt{\frac{B_{A} \cdot \lambda}{B_{F}}}=5+\sqrt{\frac{57,39.5}{22,19}}=5+12,93=17,93 \text { menit }
$$

Tingakat pelayanan optimal pada pompa pertamax

$$
\text { Optimal }=\lambda+\sqrt{\frac{B_{A} \cdot \lambda}{B_{F}}}=6+\sqrt{\frac{57,39.6}{22,19}}=6+15,51=21,51 \text { menit }
$$

Dengan Analisis Multi Kanal Fase Tunggal

Diketahui :

$$
\begin{aligned}
& \lambda=22,19 \text { Menit } \\
& \mu=57,39 \text { Menit } \\
& \mathrm{k}=6
\end{aligned}
$$

Tingkat kesibukan sistem

$$
P=\frac{\lambda}{k \cdot \mu}=P=\frac{22,19}{6.57,39} P=0,07
$$


Probabilitas tidak ada pelanggan dalam sistem $\left(P_{0}\right)$

$$
\begin{aligned}
& P_{0}= \\
& \sum_{n=0}^{k-1}\left[\frac{1}{n !}\left(\frac{\lambda}{\mu}\right)^{n}\right]+\frac{\left(\frac{\lambda}{\mu}\right)^{k}}{k !\left(1-\frac{\lambda}{k \cdot \mu}\right)}=\overline{\left[\frac{1}{0 !\left(\frac{22,19}{57,39}\right)^{0}+\frac{\left(\frac{22,19}{57,39}\right)^{6}}{6 !\left(1-\frac{22,19}{6.57,39}\right)}}\right]} \\
& =\frac{1}{[1+0,39]+\left[\frac{3,04}{5,58}\right]}=\frac{1}{1,94}=0,51
\end{aligned}
$$

bilitas pelanggan yang datang harus menunggu $\left(P_{n}\right)$

$$
\begin{aligned}
& P_{n(n-k)}=\left[\frac{\lambda}{\mu}\right]^{k} \frac{P_{0}}{k !\left[1-\frac{\lambda}{k \cdot \mu}\right]}\left[\frac{22,19}{57,39}\right]_{=}^{6} \frac{0,51}{6 !\left[1-\frac{22,19}{6.57,39}\right]}=3,04+\frac{0,51}{5,58} \\
& =3,04+0,09=3,13
\end{aligned}
$$

Rata-rata jumlah pelanggan dalam garis tunggu atau panjang antrian $\left({ }^{P_{A}}\right)$

$$
\begin{aligned}
& P_{A}=\frac{\left[\frac{\lambda}{\mu}\right]^{k} \lambda \cdot \mu}{(k-1) !(k \cdot \mu-\lambda)^{2}} \cdot P_{0}=\frac{\left[\frac{22,19}{57,39}\right]^{6} 22,19 \cdot 57,39}{(6-1) !(6 \times 57,39-22,19)^{2}} \cdot 0,51= \\
& \frac{3,04 \times 1,27}{5(211,2)} \cdot 0,51 \\
& =\frac{3,86}{1,06} \cdot 0,51=1,86 \text { pelanggan. }
\end{aligned}
$$

Waktu rata-rata pelanggan di garis tunggu atau waktu antri $\left({ }^{W_{A}}\right)$

$$
W_{A}=\frac{P_{A}}{\lambda}=\frac{1,86}{22,19}=0,08 \text { menit }
$$

Waktu rata-rata pelanggan dalam sistem $\left(W_{S}\right)$

$$
W_{S}=W_{A}+\frac{1}{\mu}=0,08+\frac{1}{57,39}=0,09 \text { menit }
$$

Jumlah rata-rata pelanggan dalam sistem atau panjang sistem $\left({ }^{P_{S}}\right)$

$$
P_{S}=P_{A}+\frac{\lambda}{\mu}
$$




$$
\begin{aligned}
& P_{S}=1,86+\frac{22,19}{57,39} \\
& P_{S}=2,25 \text { pelanggan. }
\end{aligned}
$$

\subsection{Analisis Panjang Garis Tunggu Terbatas}

Diketahui :

$$
\begin{aligned}
& \lambda=22,19 \text { menit } \\
& \mu=57,39 \text { menit } \\
& M=6
\end{aligned}
$$

Probabilitas sistem sedang kosong $\left(P_{0}\right)$

$$
\begin{aligned}
& P_{0}=\frac{1-P}{1=P^{M+1}}=\frac{1-0,39}{1-0,39^{6+1}} \\
& =\frac{0,61}{1,19}=0,51
\end{aligned}
$$

Rata-rata pelanggan di dalam sistem $\left(P_{S}\right)$

$$
P_{S}=\frac{P}{1-P}-\frac{(M+1) P^{M+1}}{1-P^{M+1}}=\frac{0,39}{0,61}-\frac{(6+1) 0,39^{6+1}}{1-0,39^{6+1}} \quad=0,64-43,84=43,2
$$

Pelanggan.

Rata-rata pelanggan di garis tunggu $\left(P_{A}\right)$

$$
P_{A}=43,2-(1-0,39)=42,59 P_{A}=42,59 \text { Pelanggan. }
$$

Waktu rata-rata pelanggan di dalam sistem $\left(W_{S}\right)$

$$
W_{S}=\frac{P_{S}}{\lambda\left(1-P_{M}\right)}=\frac{43,2}{22,19(1-0,39)}=\frac{43,2}{13,54}=3,19 \text { menit }
$$

Waktu rata-rata pelanggan di dalam garis tunggu $\left(W_{A}\right)$

$$
W_{A}=\frac{P_{A}}{\lambda\left(1-P_{M}\right)}=\frac{42,59}{22,19(1-0,39)}=\frac{42,59}{13,54}=3,15 \text { menit }
$$

\subsection{Hasil Analisis Tingkat Pelayanan Optimal}

Diketahui:

$$
\begin{aligned}
& \lambda=22,19 \text { Menit } \\
& \mu=57,39 \text { Menit }
\end{aligned}
$$

Hasil analisis tingkat pelayanan optimal dapat dilihat pada Tabel 7.

Tabel 7 Hasil Analisis Tingkat Pelayanan Optimal

\begin{tabular}{ccc}
\hline No & Pompa pengisian & Hasil (menit) \\
\hline 1 & Pompa pengisian premium roda 2 & 7,17 \\
2 & Pompa pengisian premium roda 4 & 21,51 \\
\hline
\end{tabular}




\begin{tabular}{lll}
\hline 3 & Pompa pengisian solar roda 4 & 17,93 \\
4 & Pompa pengisian pertamax & 21,51 \\
\hline
\end{tabular}

\subsection{Hasil Analisis Multi Kanal Fase Tunggal}

Diketahui:

$\lambda=22,19$ menit; $\mu=57,39$ menit dan $\mathrm{k}=6$

Hasil analisis multi kanal fase tunggal dapat dilihat pada Tabel 8 .

Tabel 8 Hasil Analisis Multi Kanal Fase Tunggal

\begin{tabular}{cccccccc}
\hline No & $P$ & $P_{0}$ & $P_{n}$ & $P_{A}$ & $W_{A}$ (menit) & $\begin{array}{c}W_{S} \\
\text { (menit) }\end{array}$ & $P_{S}$ \\
\hline 1 & 0,07 & 0,15 & 3,13 & 1,86 & 0,08 & 0,09 & 2,25 \\
\hline
\end{tabular}

\subsection{Hasil Analisis Panjang Garis Tunggu Terbatas}

Diketahui:

$\lambda=22,19$ Menit

$\mu=57,39$ Menit

$\mathrm{M}=6$

Hasil analisis panjang garis tunggu terbatas dapat dilihat pada Tabel 9.

Tabel 9 Hasil Analisis Panjang Garis Tunggu Terbatas

\begin{tabular}{cccccc}
\hline No & $P_{0}$ & $P_{A}$ & $W_{A}$ (menit) & $W_{S}$ (menit) & $P_{S}$ \\
\hline 1 & 0,51 & 42,59 & 3,15 & 3,19 & 43,2 \\
\hline
\end{tabular}

Berikut ringkasan perhitungan berdasarkan dari hasil perhitungan dan pengolahan data antrian, yang dapat dilihat pada Tabel 10-Tabel 13.

- $\lambda=22,19$ Menit.

- $\quad \mu=57,39$ Menit.

Dari hasil perhitungan $\lambda$ dan $\mu$ maka di dapatkan hasil perhitungan sebagai berikut:

Tabel 10 Rata-Rata Antrian Pada Pompa Premium Kendaraan Roda Dua

\begin{tabular}{ccccc}
\hline P0 & Ls (menit) & Lq (menit) & Ws (menit) & Wq (menit) \\
\hline 0,87500 & 0,13393 & 0,00060 & 0,06696 & 0,00030 \\
0,87500 & 0,13393 & 0,00060 & 0,06696 & 0,00030 \\
0,86667 & 0,15385 & 0,02051 & 0,07692 & 0,01026 \\
0,86667 & 0,15385 & 0,02051 & 0,07692 & 0,01026 \\
\hline
\end{tabular}

Tabel 11 Rata-Rata Antrian Pada Pompa Premium Kendaraan Roda Empat

\begin{tabular}{ccccc}
\hline P0 & Ls (menit) & Lq (menit) & Ws (menit) & Wq (menit) \\
\hline 0,64706 & 0,44920 & 0,02063 & 0,07487 & 0,00344 \\
0,64706 & 0,44920 & 0,02063 & 0,07487 & 0,00344 \\
0,57143 & 0,75000 & 0,32143 & 0,12500 & 0,05357 \\
0,57143 & 0,75000 & 0,32143 & 0,12500 & 0,05357 \\
\hline
\end{tabular}

Tabel 12 Rata-Rata Antrian Pada Pompa Solar Kendaraan Roda Empat

\begin{tabular}{ccccc}
\hline P0 & Ls (menit) & Lq (menit) & Ws (menit) & Wq (menit) \\
\hline 0,69697 & 0,36891 & 0,01176 & 0,07378 & 0,00235 \\
0,69697 & 0,36891 & 0,01176 & 0,07378 & 0,00235 \\
0,64286 & 0,55556 & 0,19841 & 0,11111 & 0,03968 \\
\hline
\end{tabular}




\begin{tabular}{ccccc}
\hline 0,64286 & 0,55556 & 0,19841 & 0,11111 & 0,03968 \\
\hline \multicolumn{5}{c}{ Tebel 13 Rata-Rata Antrian Pada Pompa Pertamax } \\
\hline P0 & Ls (menit) & Lq (menit) & Ws (menit) & Wq (menit) \\
\hline 0,62500 & 0,48750 & 0,02596 & 0,08125 & 0,00433 \\
0,62500 & 0,48750 & 0,02596 & 0,08125 & 0,00433 \\
0,53846 & 0,85714 & 0,39560 & 0,14286 & 0,06593 \\
0,53846 & 0,85714 & 0,39560 & 0,14286 & 0,06593 \\
\hline
\end{tabular}

Keterangan:

P0 =Probabilitas sistem sedang kosong

Ls $=$ Jumlah pelanggan dalam sistem (pelanggan)

$\mathrm{Lq}=$ jumlah pelanggan yang menunggu dalam antrian (pelanggan)

$\mathrm{Ws}=$ Waktu rata-rata pelanggan dalam sistem (menit)

$\mathrm{Wq}=$ Waktu menunggu selama pelanggan dalam antrian (menit)

\section{KESIMPULAN}

Adapun kesimpulan dari penelitian adalah sebagai berikut:

1. Laju kedatangan kendaraan pada setiap pompa adalah pompa pengisian premium roda 2 adalah 2.59 menit. Pompa pengisian premium roda 4 adalah 6.98. Pompa pengisian solar roda 4 adalah 5.97 menit dan pompa pengisian pertamax adalah 6.65 menit dengan jumlah fasilitas 1 .

2. Laju pelayanan kendaraan pada pompa yaitu pompa pengisian premium roda 2 dan roda 4 adalah 15.52 menit dan 14.11 menit, pompa pengisian solar roda 4 adalah 14.21 menit dan pompa pengisian pertamax adalah 13.55 menit.

3. Rancangan skenario pada pada setiap pompa adalah Skenario 1 dengan 2 pompa, Probabilitas sistem sedang kosong 0,87500, Jumlah pelanggan dalam sistem dan jumlah pelanggan yang menunggu dalam antrian masing-masing 1 pelanggan, Waktu rata-rata pelanggan dalam sistem 0,06696 menit dan Waktu menunggu selama pelanggan dalam antrian 0,00030 menit. Yang selengkapnya dapat dilihat pada Tabel 4,5,6 dan Tabel 7.

4. Tingkat pelayanan yang optimal yaitu Ppmpa pengisian premium roda 2 dan roda 4 7,17 menit dan 21,51 menit Pompa pengisian solar roda 4 adalah 17,93 menit dan Pompa pengisian pertamax adalah 21,51 menit.

5. Panjang garis tunggu pada antrian probabilitas sistem sedang kosong 0,51 , Waktu rata-rata pelanggan dalam sistem 3,19 Menit.

6. Fasilitas pengisian kendaraan roda dua maupun roda empat adalah pompa pengisian premium roda 2 dan roda 4 yaitu masing-Masing 2 dan pompa pengisian solar roda 4 dan pompa pengisian pertamax dengan jumlah fasilitas masing-masing 1.

7. Rata-rata antrian pada pompa premium kendaraan roda dua yaitu probabilitas sistem sedang kosong 0,87500 dan 0,86667 dengan jumlah pelanggan dalam sistem 0,13393 yaitu 1 pelanggan, jumlah pelanggan yang menunggu dalam antrian 0,00060 yaitu 1 pelanggan, Waktu rata-rata pelanggan dalam sistem 0,06696 menit dan 0,07692 menit, waktu menunggu selama pelanggan dalam antrian 0,00030 menit dan 0,01026 menit. 


\section{DAFTAR PUSTAKA}

[1]. Schroeder, Roger G., 2007, Operations Management: Contemporary Concepts and Cases, 3rd ed., McGraw-Hill, Singapore.

[2]. D.Wahyuni Ariani, 2009. "Manajemen Operasional Jasa”, Graha Ilmu, Yogyakarta.

[3]. Richard B. Chase, 2006. "Operation Management For Competitive Advantage", Internasional Edition New York : McGrawHill.

[4]. Elis Ratna Wulan dan Neng Sri Wahyuni,2015. "Model Antrian Multi Server $\left(M^{[X]} / M / C ; C-1 / F C F S\right)$ Gangguan Pelayanan Dengan Pola Kedatangan Berkelompok” JURNAL ISTEK, edisi Juni 2015 Volume IX No. 1, Universitas Islam Negri Sunan Djati Bandung.

[5]. Render B, 2008. "Operations Management, 9th edition. New Jersey: Prentice Hall". 